2. Herr Ch. Edler ron Schickb an den Redacteur der deutschen Zeitung in Wien.

Herr Redacteur! Als icb ron der obigen Zuscbrift Kenntniss genommen, scbrieb ich an Herrn Professor Dr. G. Jäg er um näheren Aufschluss, weil ich selbst mich dem gleichen Punkte auf dem naturwissenscbaftlicben Erkenntnissfelde in meinen Arbeiten zugewendet hatte und daber das grüsste Interesse an allem darauf Bezïglicben nabm. - Ich erhieit nun folgendes Antw ortschreiben:

3. ,Geehrter Herr! Den thatsächlichen Nachweis ron der Richtigkeit meiner Bebaupting, dass die Dichtstoffe, die man an einem lebenden Geschïpfe riecbt, die Seele sind, babe ich dadurch geliefert, dass icb mittelst eines sehr feinen Zeitmessers die Geschwindigkeit der Nervenleitung nacb einer in der Experimental-Physiologie längst gebräuchlichen Methode prüfte. So konnte ich ziffermässig nachweisen, dass die genannten Dichtstoffe in intensivster Weise auf das Nervensystem wirken und dass sie die Erzeuger der. Seelenaffecte" sind, und zwar in doppelter Weise: ein Gescböpf kommt in Affect: 1. wenu i, ihm selbst der Dichtstoff seines eigenen Eiweisses entbunden wird: w w es diesell Dichtstoff oder den entsprechenden einer andern Die Experimente sind in der mannigfaltigsten Weise variirt worden und lassen für den Fachmann nicht den mindesten Zweifel mehr übrig. In der in Kurzem erscheinenden $z$ weiten Auflage meiner Scbrift. . Entdeckung der Seele werden alle Nachweise und neue, ungeahnte Aufschliisse enthalten sein, auch einige interessante Angaben über Natur und Wesen des Geistes, der sich mit rölliger Klarheit als etwas real Existirendes, von der Seele toto e coelo Verschiedenes beransstellt. Die materialistiscbe Lehre erhält durch meine Entdeckung einen Schlag, ron dem sie sich scbwerlich wieder erholen wird,

\section{Die Entdeckung der Seele durch Herrn Prof. Jäger.} Ein kurioser Briefwecbsel.

1. Prof. Jäger an den Herausgeber des Auslands Herrn v. Hellwald. "Stuttgart, 11. Mai 1879 . Werthester Freund! Da ich weiss, dass Sie sich für meine „Entdeckung der Seele ${ }^{\star}$ lebbaft interessiren, wird Ihnen vielleicht die kurze Notiz willkommen sein, dass es mir beute, nacbdem mein Chronoskop seit acbt Tagen im Gang, gelumgen ist, den mathematiscben Beweis für den Knotenpunkt meiner Entdeckung in wünscbenswertbester Weise zu führen. Auf der nächsten Naturforscher-Versammlung in Baden-Baden werde ich die Seele an Händen und Füssen mathematisch gaden-Baden Gelebrten-Areopag ad oculos, ad nares et ad manum demonstriren. Mit besten Grüssen Ihr Dr. G. Jäge r. “ und die practischen Früchte meiner Entdeckung, die ich bereits in vollsten Zügen geniesse, werden meiner Entdeckung den Triumph schneller erringeu, als irgend einer andern Entdeckung ron ähnlicher 'Tragweite, whesholl der Blödsinn, mit dem anonyme Feuilletonisten meinen Brief an Hellwald zu garniren für gut finden, blos erheiternd auf mich wirkt.

Stuttgart. am 7. Juni 1879. Mit besten Grïssen Ihr ergebenster Dr. G. Jäger.

Wir halten vorläufig, sagt die W. Med. Pr., der wir diese Correspondenz entnehmell, das Ganze für eine gelungene Satyre, wenn nicht gar für Selbstironisirung, da jedoch die Sache so rielfach besprochen wird, glaubten
wir, selbe den Lesern nicbt wir, selbe den Lesern nicbt vorentbalten zu sollen. 